\title{
The Development of an Automated System in Detecting Environmental Data for the Monitoring of Forest Activity
}

\author{
Shahrizuan Shafiril, Amri Yusoff, and Norma Che Yusoff
}

\begin{abstract}
Forest ecosystems have always received worldwide attention due to their biological diversity and these forests are vital for human existence. However, the area is decreasing due to human negligence and over-exploitation by the human population. Recent reports show evidences of illegal logging and harvesting activities through the collection of environmental data. This research characterizes the dynamics, cycle of temperature, humidity, and phase particles of a prototype device for data collection. The hardware components for this prototype will consist of temperature and humidity sensors, solar Lipo Rider for self-powering device and phase particle sensors. Sensor data has been identified as salient data for the preservation and protection of the biological ecosystem, in terms of population wellbeing and prolonged heritage. Therefore, the development of this Automated System Detecting Environment (ASDE) will be useful in assisting regulatory bodies, researchers and ecologists to identify changes within the ecosystem.
\end{abstract}

Index Terms-Arduino, environmental remote monitoring, forest monitoring, sensor ecosystem.

\section{INTRODUCTION}

As of late, our world is faced with rapidly deteriorating and irreversible ecosystems changes that are either done deliberately or due to human negligence at a global scale. This will result in the emergence of unhealthy phenomena such as smog, global warming or flash floods [1], [2]. Whenever weather conditions prevent smoke and other pollutants from disperse, it thickens and forms a veil that usually lingers in the air, consequently affecting vision and causes respiratory health threats. Other major contributors for causing thick haze may come from the gaseous pollutants of industrial by-products. The Air Pollution Index (API) is one way to determine the level of severity of the haze. It involves the quantity measurement of hazardous fine particles such as carbon monoxide, sulfur dioxide, nitrogen dioxide and ozone. Separate devices are required to purposely measure each distinctive parameter such as digital thermometer to read the temperature, particle counter to count the number of particles in the air and gas detector to identify poisonous gases. Currently, the environmental device for gathering meteorological data at the Meteorological Department does not combine all of the weather equipment into a single device,

Manuscript received August 19, 2015; revised September 9, 2015. This research was supported by Malaysian Ministry of Education under the ERGS Grant no 2013-0091-108-22.

Shahrizuan Shafiril and Amri Yusoff are with Universiti Pendidikan Sultan Idris, Malaysia (e-mail: cloudywolfshah86@yahoo.com, amri@fskik.upsi.edu.my).

Norma Che Yusoff is with the Institute of Biological Sciences, Faculty of Science, University of Malaya, Malaysia (e-mail: ynorma@um.edu.my). thus making it difficult to see the relation between harmful particles, gases, temperature and humidity. Therefore, it is useful to develop a single handy device that is fully automated and can easily capture all these measurement data and transmit them in real-time for correct analysis. Ideally, it would be significant if this single device is equipped with self-generating power such that it can be used in remote areas such as in forests for remote data logging. This newly developed prototype is the Automated System in Detecting Environmental data (ASDE). The main features of this system include:

- An upgrade to the existing meteorological instruments.

- To develop a meteorological device that is both mobile and automatic

- A means to reduce the problems faced by the researchers to obtain data

This study focuses on the gathering of a unified data for temperature, humidity and air pollution for ecological phenomenon such as haze that often occurs when dust and smoke particles accumulate in relatively dry air. Hopefully, this design will become a benchmark test bed study for further improvements in more comprehensive devices that can be used for data monitoring by researchers in the field.

\section{The Existing Method of Data Collection}

Forecast weather and conditions are often mentioned in the field of meteorology. Weather is the condition of the atmosphere at a particular time and location. The atmospheric conditions normally include temperature, humidity, pressure, wind speed and direction. But the ongoing model prototype that had been developed includes only three measurements which are temperature, humidity and air pollution index only. Further improvements on the device in the future will include all mentioned major measurements for atmospheric conditions. Some of the features of the climate in Malaysia are uniform temperature, high humidity and abundant rainfall. Winds are generally light. Malaysia is located in the equatorial doldrums that is rarely to have clear skies even in periods of severe drought. It is also rare for Malaysia to have a few days with no sunshine except during the northeast monsoon season. Although generally light and variable, there are changes in the wind patterns as Malaysia experiences four seasons of change i.e. the southwest monsoon, northeast monsoon and two shorter periods between monsoons. These are the tools that are commonly used by the Meteorological Department for measuring weather data at the observation stations:

\section{A. Automated Weather System (AWS)}

In line with recent technologies, the observation equipment 
has become fully automated [3]. The automated weather observation system consists of the following components:

- A set of meteorological sensors placed in protective equipment and connected to the processing unit (data-logger) with independently wrapped cable.

- A processing unit (data-logger) used for data acquisition, processing, storage and transmission;

- The auxiliary equipment such as stabilizer power source, modem, built-in diagnostics, and local terminal for manual data entry, editing and viewing data.

The AWS measures the amount of rainfall, air pressure, temperature, humidity, wind speed and direction as well as global radiation, which is also updated every minute, 24 hours a day without human assistance [4].

\section{B. Wind Direction and Speed Indicator}

Wind direction is determined by the direction of the wind blowing. It is displayed in degrees and measured clockwise from the north. A wind vane is used to indicate or to record surface wind direction. Wind speed is measured in meters per second or knots. If the wind speed is less than one meter per second or two knots, wind indicators will only give reading as calm. Usually, calm condition is indicated if the wind speed is less than 0.5 meters per second, or less than one knot [5]. The equipment used to measure wind speed is called an anemometer. One of the most commonly used types of anemometer is the cup anemometer. It is formed of three cups all in hemispheres. The pressure differences between the cups will cause the cup to rotate [6] and the wind rate is calculated based on the rotation speed of the wind per time.

\section{Temperature Gauges}

Temperature gauges are used for measuring temperature and give a fairly accurate temperature due to the usage of internal circuit technologies combined with platinum resistance thermometer elements [7]. The Stevenson screen is one of the equipment used to indicate temperature and humidity. The Stevenson system consists of wet and dry bulb thermometers which are supported vertically from the inside of the shelter. The bulb thermometer is wrapped in wet muslin cloth and tied with a thread placed in a reservoir filled with distilled water. This system collects the humidity data and dew points by analysing the moisture change inside the shelter.

\section{Solarimeter/Pyranometer}

The solarimeter is used to measure solar radiation at the Earth's surface on a regular basis. It has a thermocouple sensor element. The detector element is coated with stable inorganic carbon which can give the absorption spectrum and stability characteristics for a long time [8]. The detector elements are usually placed under the glass dome.

\section{E. Air Pressure Measurement}

The normal pressure is calculated based on the pressure capsule or solid state capacitive device whose output voltage is digitally encoded prior transfer to the air pressure [9]. The weather equipment used in Malaysia can be improved and refined further so that it gives more effective and accurate real time data and in the future. Furthermore, this data can be integrated with cloud storages for more innovative information gathering as the data collection can be shared over the internet [10]. The proposed system is being developed and designed to cater for this technology such that it is fully applicable in the Automated System for Detecting Environment (ASDE) data. The complete system will have the combination of all the systems plus the improvement in data collection techniques, portability and scaled to a smaller size, self-powered by solar, and can replace the present equipment.

\section{The Design Model OF ASDE}

Fig. 1 is the Automated System for Detecting Environment (ASDE) proposed system explained in block diagram.

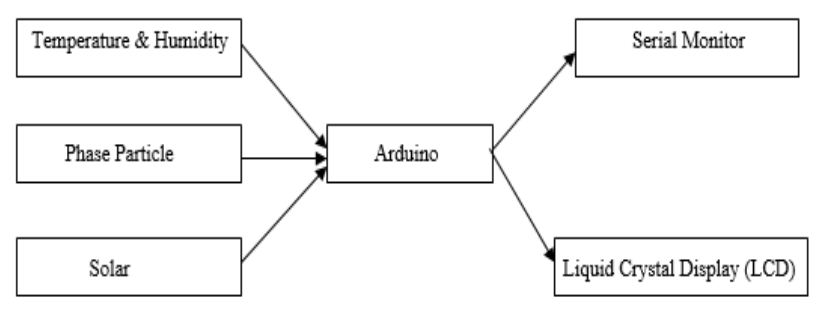

Fig. 1. The proposed system for ASDE.

The complete prototype of ASDE is shown in Fig. 2 while Fig. 3 is the part of the programs that been created. The detailed explanation for each block diagram is as follows:

\section{A. Input}

There are three inputs used to collect the environmental data and one input for absorbing solar in order to self-power the device.

\section{1) Temperature and humidity}

This module is for the detection of temperature and humidity. These data are measured in analog and the sensor needed to be configured internally and programmed by the controller before it is used. The measurement of temperature and humidity can be read out through the Serial Monitor via USB port on a personal computer or displayed on LCD display located in the front of the system

\section{2) Solar}

This module is the power supply module for the system. The system does not require any external power as the system is self-powered by solar. This proved to be handy because the system does not need regular maintenance such as battery replacements by the operator or a periodic inspection on the existing device. Solar LiPo Rider Pro will supply the power to the controller as well as charge the internal battery via the solar panel located on the top of the ASDE. This module also acts as the power switch to turn on/off the ASDE.

\section{3) Phase particle}

This module is the detection system for air pollution such as haze that often occurs when dust and smoke particles accumulate. This sensor will detect particles using a unit measurement value of $(\mu \mathrm{g} / \mathrm{m})$.

\section{4) Arduino controller}

The controller used in this device is the development board for Programmable Integrated Circuit. This section will handle all the necessary inputs and transfer the data to the output. All 
the data measurements are calculated by the controller. The algorithm program can be downloaded via USB without the need to open the casing. The transfer rate is fast and can be read and write and is erasable of up to 2 kilobytes of memory.

\section{B. Output}

There are 2 outputs used in this device: LCD and Serial Monitor.

\section{1) $L C D$}

LCD stands for Liquid Crystal Display. The reading of temperature, humidity and phase particle will be displayed on a $2 " \times 16 "$ screen with alphanumeric characters and LED backlight. The measurement readings display will change alternately after 10 seconds following the order of temperature, humidity and phase particle.

\section{2) Serial monitor}

The readings can also be displayed through a serial monitor from a PC or laptop using special debugging software provided by the controller.

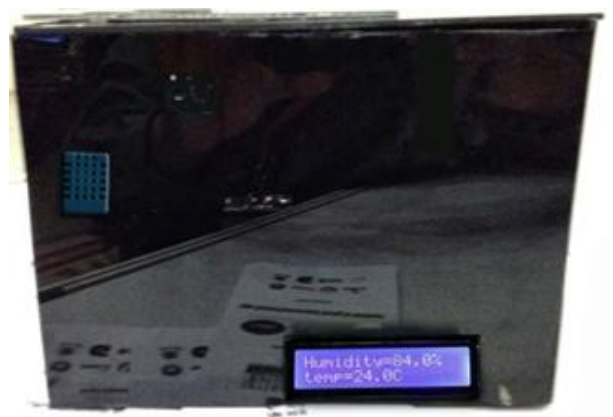

Fig. 2. The complete prototype of ASDE.

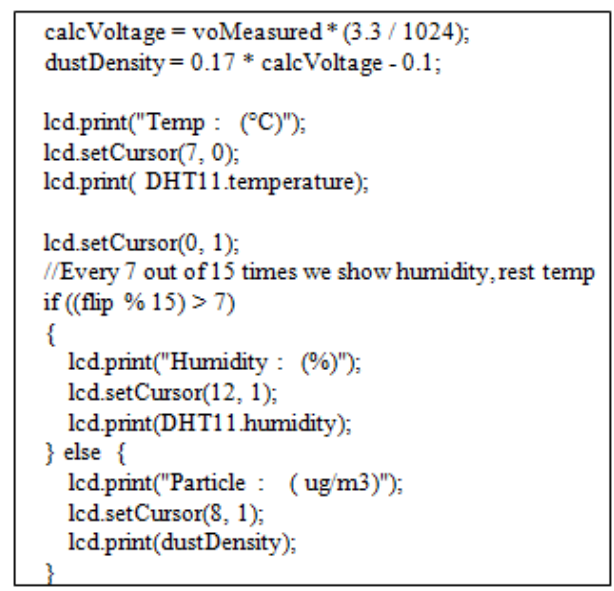

Fig. 3. An example of program inside the controller.

\section{HARDWARE COMPONENTS INSIDE ASDE}

Below is the list and detailed explanations of the hardware used in the construction of the ASDE prototype.

\section{A. Arduino}

Arduino board in Fig. 4 has been selected for the controller due to several advantages. Some of its benefits are open-source, software and hardware is easily accessible and flexible in customization and expansion. Arduino offers a variety of digital and analog inputs, SPI and serial interface and digital and PWM outputs. It is easy to use, connects to computer via USB and communicates using standard serial protocol, runs in standalone mode and as interface connected to computers. It is inexpensive and comes with free authoring software Arduino and fully supported by a growing online community. Also with many online examples of source code and we can share and post our examples for others to view and help.

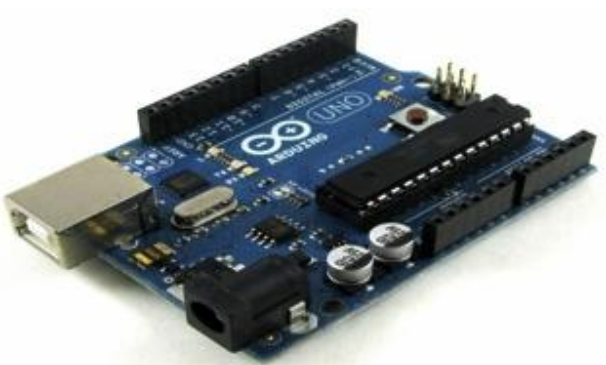

Fig. 4. Arduino Uno as the control board.

\section{1) Detail information of arduino as control board}

An Arduino is an open-source microcontroller development board. You can use the Arduino to read sensors and control things like motors and lights. This allows you to upload programs to this board which can then interact with things in the real world. With this, you can make devices which respond and react to the external source. For instance, you can read a humidity sensor connected to a potted plant and turn on an automatic watering system if it gets too dry. Or, you can make a stand-alone chat server which is plugged into your internet router. Or, you can have it tweet every time your cat passes through a pet door. Or, you can have it start a pot of coffee when your alarm goes off in the morning. Basically, if there is something that is in any way need to be controlled manually, the Arduino can interface with it in some manner. And even if it is not controlled by electricity, you can probably still use things which are (like motors and electromagnets), to interface with it. Table I shows the Arduino Specification.

\begin{tabular}{|l|l|}
\multicolumn{2}{c|}{ TABLE I: ARDUINO SPECIFICATION } \\
\hline \multirow{2}{*}{ No. } & Specification \\
\cline { 2 - 2 } & Arduino Uno \\
\hline 1 & ATmega328 microcontroller \\
\hline 2 & Input voltage - 7-12V \\
\hline 3 & 14 Digital I/O Pins (6 PWM outputs) \\
\hline 4 & $16 \mathrm{Mhz}$ Clock Speed \\
\hline
\end{tabular}

\section{2) Advantages of using Arduino as control board}

- Debugging:-The Arduino environment provide easiest debugging environment which is cross-platform and is accepted by every member of the family of processors.

- No need of external programmer for uploading the program.

- Rich in examples to write simple functions for examples function for delay or interrupt.

- Robust in design and not easily break with no hardware faulty.

- Ready-made external peripherals and Modular shield to support dedicated services for example simply adding plug and play motor shields to the board without any wire to run DC motor. Other shields available are Bluetooth and Wi-Fi shield for wireless and internet communication.

- A large pool of repository software and hardware libraries 
that can be integrated with the main board.

\section{B. DHT 11 Temperature and Humidity Sensor}

The DHT11 in Fig. 5 is a basic, low-cost digital temperature and humidity sensor. It uses a capacitive humidity sensor and a thermistor to measure the surrounding air, and generate a digital signal output on the data pin (no analog input pins needed). It is fairly simple to use, but requires careful timing to detect data. The only limitation on this sensor is you can only get new data from it once every 2 seconds.

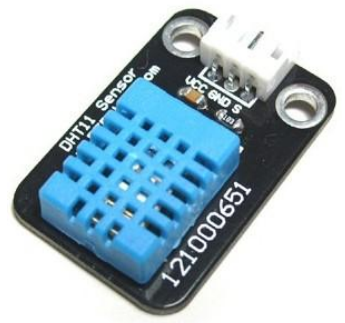

Fig. 5. DHT11 temperature and humidity sensor.

\section{1) Detail information of DHT11 temperature and humidity sensor}

This sensor includes a resistive-type humidity measurement component and temperature measurement component, and connects to a high-performance 8-bit microcontroller, offering excellent quality, fast response, anti-interference ability and cost-effectiveness. DHT11 has been calibrated in the laboratory in order to give an accurate result. The calibration coefficients are stored as constant in the OTP memory, which are used by the sensor's internal signal while detecting process. The single-wire serial interface makes system easy to connect to the controller board Its small size, low power consumption and up-to-20 meter signal transmission making it the best choice for temperature and humidity applications. Table II shows the detail specification for DHT11.

TABLE II: DHT 11 SPECIFICATIONS

\begin{tabular}{|c|c|c|c|c|c|}
\hline No. & \multicolumn{5}{|l|}{ Specification } \\
\hline & Parameters & Conditions & Min. & $\begin{array}{l}\text { Typica } \\
l\end{array}$ & Max. \\
\hline 1 & Humidity & & & & \\
\hline 2 & Resolution & & $1 \% \mathrm{RH}$ & $1 \% \mathrm{RH}$ & $1 \% \mathrm{RH}$ \\
\hline 3 & Repeatability & & & $1 \% \mathrm{RH}$ & \\
\hline \multirow[t]{2}{*}{4} & \multirow[t]{2}{*}{ Accuracy } & $25^{\prime} \mathrm{C}$ & & $4 \% \mathrm{RH}$ & \\
\hline & & $0-50 ’ \mathrm{C}$ & & & $5 \% \mathrm{RH}$ \\
\hline 5 & $\begin{array}{l}\text { Interchange } \\
\text { ability }\end{array}$ & \multicolumn{4}{|c|}{ Fully Interchangeable } \\
\hline \multirow[t]{3}{*}{6} & \multirow{3}{*}{$\begin{array}{l}\text { Measurement } \\
\text { Range }\end{array}$} & $0^{\prime} \mathrm{C}$ & $30 \% \mathrm{RH}$ & & $90 \% \mathrm{RH}$ \\
\hline & & $25^{\prime} \mathrm{C}$ & $20 \% \mathrm{RH}$ & & $90 \% \mathrm{RH}$ \\
\hline & & $50 ’ \mathrm{C}$ & $20 \% \mathrm{RH}$ & & $80 \% \mathrm{RH}$ \\
\hline 7 & $\begin{array}{l}\text { Respond Time } \\
\text { (Seconds) }\end{array}$ & $\begin{array}{l}\text { 1/e(63\%)25 } \\
\text { 'C, } 1 \mathrm{~m} / \mathrm{s} \text { Air }\end{array}$ & $6 s$ & $10 \mathrm{~s}$ & $15 \mathrm{~s}$ \\
\hline 8 & Hysteresis & & & $1 \% \mathrm{RH}$ & \\
\hline 9 & $\begin{array}{l}\text { Long-Term } \\
\text { Stability }\end{array}$ & Typical & & $\begin{array}{l}1 \% \mathrm{RH} \\
\text { /year }\end{array}$ & \\
\hline 10 & Temperature & & $1 ' \mathrm{C}$ & $1^{\prime} \mathrm{C}$ & $1^{\prime} \mathrm{C}$ \\
\hline 11 & Resolution & & 8 Bit & 8 Bit & 8 Bit \\
\hline
\end{tabular}

\section{2) Advantages of using DHT11}

DHT11 has an excellent quality, fast response, anti-interference ability and gives a high value performance. Moreover, it is to implement and simple to use. This sensor gives better accuracy when compares to infrared thermometer). Furthermore, it is capable of measuring temperature accurately as far as 20 meters away from the sensor. The distance can be increased further by reducing the pull-up resistor value.

\section{Phase Particle Sensor (GP2Y1010AUOF)}

Phase Particle sensor in Fig. 6 composes of a sensing device that measures the air quality in the surrounding environment. This sensor uses an optical air quality sensor and it is designed to sense dust particles. An infrared emitting diode and a phototransistor are diagonally arranged into this device allowing it to detect the reflected light of dust in air. It is especially effective in detecting very fine particles like smoke dusts, and is commonly used in air purifier systems.
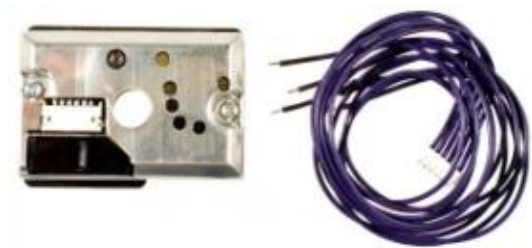

Fig. 6. Phase particle sensor(GP2Y1010AU0F).

\section{1) Advantages of using particle phase sensor}

The sensor has a very low current consumption (20mA max, $11 \mathrm{~mA}$ typical), and can be powered with up to 7VDC. The output of the sensor is an analog voltage proportional to the measured dust density, with a sensitivity of $0.5 \mathrm{~V} / 0.1 \mathrm{mg} / \mathrm{m} 3$.

\section{Solar (LiPo Rider Pro)}

The solar device in Fig. 7 is used to power and to backup supply to the ASDE. Table III shows the detail specifications for Solar LiPo Rider Pro.

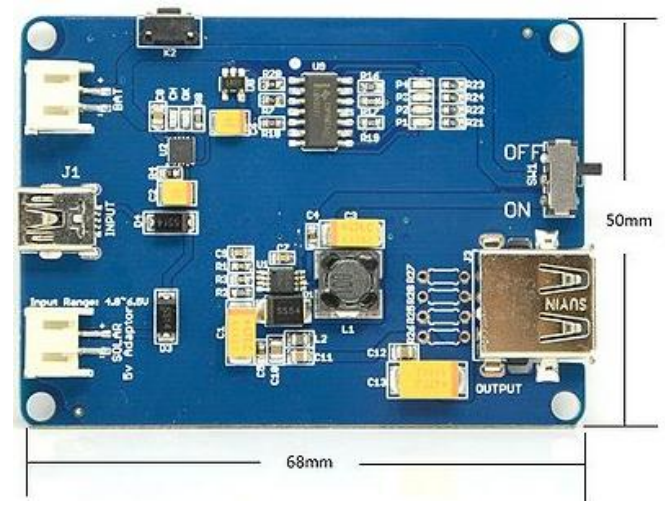

Fig. 7. Solar (LiPo Rider Pro).

TABLE III: SOLAR LIPO RIDER PRO SPECIFICATION

\begin{tabular}{|l|l|}
\hline \multirow{2}{*}{ No. } & Specification \\
\cline { 2 - 3 } & LiPo Rider Pro \\
\hline 1 & Up to 400m A charge current \\
\hline 2 & Up to 5v 350m A supply ability \\
\hline 3 & $\begin{array}{l}\text { Less than } 100 \mathrm{mV} \text { ripple @ } \\
300 \mathrm{~mA}\end{array}$ \\
\hline 4 & Dimension: $47 * 37.5 * 6.6(\mathrm{~mm})$ \\
\hline
\end{tabular}

The LiPo Rider Pro relatively affordable and easy to use. No programming is required. The internal charger IC handles all the power requirements for various components. If solar 
power is not sufficient, the mini USB port allows charging lithium battery through USB. It can also be used to program the controller without detaching the LiPo Rider Pro board.

\section{CONCLUSION}

The Automated System for Detecting Environment (ASDE) system is ready to be employed in the real environment using all the hardware components and software discussed. It will have the combination of all the system plus the improvement in data collection technique, portable and scale to smaller size, self-powered by solar, and can be a direction substitution to the present equipment used in meteorological department. Actual experiment shows that ASDE can detect temperature, humidity and phase particle with the 90-95\% accuracy. Researchers that currently involve in researching about deforestation and the increase of forest ecosystem temperature, humidity and phase particle may find that the data taken from the ASDE will be useful for real time analysis in investigation on what factors that contributes to global warming due to deforestation and open burning in the suspected hot spot areas.

\section{ACKNOWLEDGMENT}

We would like thanks UPSI for the opportunity to take part in EduInEri competition in submitting this study.

\section{REFERENCES}

[1] B. Brunekreef, "Air pollution and human health: From local to global issues," in Procedia - Social and Behavioral Sciences, vol. 2, pp. 6661-6669, 2010.

[2] J. O. Anderson, J. G. Thundiyil, and A. Stolbach, "Clearing the air: A review of the effects of particulate matter air pollution on human health," Journal of Medical Toxicology, vol. 8. pp. 166-175, 2012.

[3] J. Zachariassen, K. Zeller, N. Nikolov, and T. McClelland, A Review of the Forest Service Remote Automated Weather Station (RAWS) Network, 2003.

[4] R. Kuśmierek-Tomaszewska, J. Żarski, and S. Dudek, "Meteorological automated weather station data application for plant water requirements estimation," Computers and Electronics in Agriculture, vol. 88. pp. 44-51, 2012.

[5] E. N. Eastwood, G. Kocurek, D. Mohrig, and T. Swanson, "Methodology for reconstructing wind direction, wind speed and duration of wind events from aeolian cross-strata," J. Geophys. Res. F Earth Surf., vol. 117, 2012
[6] M. Caporin and J. Pre, "Modelling and forecasting wind speed intensity for weather risk management," Comput. Stat. Data Anal., vol. 56, pp. 3459-3476, 2012.

[7] Q. Cai, Y.-C. Chen, C. Tsai, and J. F. DeNatale, "Development of a platinum resistance thermometer on the silicon substrate for phase change studies," Journal of Micromechanics and Microengineering, vol. 22. p. 085012, 2012

[8] A. Sartarelli, S. Vera, R. Echarri, E. Cyrulies, and I. Sams, "Heat flux solarimeter," Sol. Energy, vol. 84, pp. 2173-2178, 2010.

[9] X. Lin and K. G. Hubbard, "Sensor and electronic biases/errors in air temperature measurements in common weather station networks," Journal of Atmospheric and Oceanic Technology, vol. 21. pp. 1025-1032, 2004.

[10] E. Erell and T. Williamson, "Simulating air temperature in an urban street canyon in all weather conditions using measured data at a reference meteorological station," Int. J. Climatol., vol. 26, pp. 1671-1694, 2006.

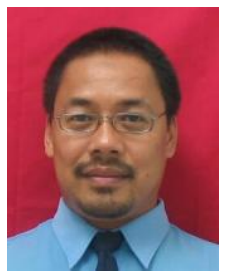

Amri Yusoff received his BSc in electrical engineering from University of Nevada, Reno, USA (1987), the MEng in information science and system engineering from Oita University, Japan (1995) and the PhD in computer science from University of Southampton, UK (2010).

He currently holds a post of a senior lecturer at University Pendidikan Sultan Idris, Perak, Malaysia from 2005. Previously he holds a position as a vice president technology at crystal clear technology sdn. bhd in charge of advanced product design after working as R\&D Enginner at Perkom Sdn Bhd. He also owned a startup company called Small Innvation System Sdn Bhd.

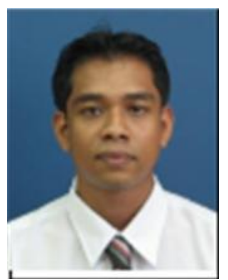

Shahrizuan Bin Shafiril was born in Klang, Selangor on April 15, 1986. His earned his degree from in computer aided design of technology (CADT) from Universiti Pendidikan Sultan Idris (2014). Currently he is pursuing the MSc in robotic technology at UPSI.

He currently is working as a research assistant and part time tutor of robotic and serious game at Universiti Pendidikan Sultan Idris (UPSI).

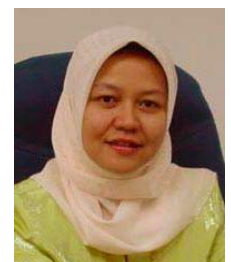

Norma Binti Che Yusoff is an avid researcher on faunistic living treasures with an extensive field experience. Her job involves four domains, teaching, research, management $\&$ administration and providing scientific services to a wider community. The central them of her research interest is behavioural ecology in the laboratory or various ecosystems (mangrove, marine, riverine, agricultural and forest) in wide ranging animals (damselflies \& dragonflies, ants, spiders, mudskippers, squirrels \& primates). Currently, she has developed a passion for various aspects (biomonitoring, biocoenosis, ecomorphometrics, systematics, behaviour and ecology) of dragonflies and spiders. She has described a myriad of species found to be new local records or new to science promoting Malaysian mega biodiversity. 